\title{
Cromito de lantânio: material para interconectores de células a combustível de óxido sólido - uma revisão
}

\section{(Lanthanum chromite: material for Solid Oxide Fuel Cell interconnects - a review)}

\author{
L.F.G.Setz' ${ }^{1}$ S.R.H.Mello-Castanho ${ }^{2}$, M.R.Morelli ${ }^{3}$ \\ ${ }^{l}$ Centro de Engenharia, Modelagem e Ciências Sociais Aplicadas, Universidade Federal do ABC, Av. dos \\ Estados 5001, Bairro Bangu, Santo André, SP, Brasil 09210-580 \\ ${ }^{2}$ Centro de Ciência e Tecnologia de Materiais, Instituto de Pesquisas Energéticas e Nucleares, Av. Prof. Lineu \\ Prestes 2242, Cidade Universitária, S. Paulo, SP, Brasil 05508-900 \\ ${ }^{3}$ Departamento de Engenharia de Materiais, Universidade Federal de S. Carlos, Rodovia Washington Luís, km \\ 235, bairro Monjolinho, S. Carlos, SP, Brasil 13565-905 \\ luiz.setz@ufabc.edu.br,srmello@ipen.br,morelli@ufscar.br
}

\begin{abstract}
Resumo
$\mathrm{O}$ cromito de lantânio $\left(\mathrm{LaCrO}_{3}\right)$ é um material cerâmico sintético, que apresenta como principais características boa condutividade elétrica em altas temperaturas $\left(>800^{\circ} \mathrm{C}\right)$, estabilidade química e física em atmosferas oxidantes e redutoras e, significativa atividade catalítica quando na forma de pós. Estas características o tornam atrativo para diversas aplicações de interesse tecnológico, como catalisadores, resistências para fornos de alta temperatura e geração de energia elétrica, sendo que nesse campo é potencialmente o material mais adequado para utilização como interconector em células a combustível de óxido sólido (Solid Oxide Fuel Cell $S O F C$ ). As características intrínsecas, propriedades e técnicas de processamento do cromito de lantânio são consideradas neste trabalho por meio de uma revisão dos principais estudos relatados ao longo dos últimos 40 anos.
\end{abstract}

Palavras-chave: cromito de lantânio, SOFC, revisão.

Abstract

The lanthanum chromite $\left(\mathrm{LaCrO}_{3}\right)$ is a synthetic ceramic material, which has as main characteristics of good electrical conductivity at high temperatures $\left(>800^{\circ} \mathrm{C}\right)$, physical and chemical stability in oxidizing and reducing atmospheres, and a significant catalytic activity when used as powder. These features make it attractive for various technological applications such as catalysts, resistance to high temperature furnaces and electric power generation, and this field is potentially the most appropriate material for use as interconnector in Solid Oxide Fuel Cells (SOFC). The intrinsic characteristics, properties and processing of lanthanum chromite are detailed in this paper through a review of major studies reported over the past 40 years.

Keywords: lanthanum chromite, SOFC, review.

\section{INTRODUÇÃO}

Material sintético de grande importância tecnológica, o cromito de lantânio ainda se destaca como o principal material capaz de conduzir eletricidade em altas temperaturas suportando diferentes tipos de atmosferas frente a materiais como os aços inoxidáveis. Neste trabalho são revisadas as características, as propriedades, as possíveis aplicações e o comportamento durante o processamento do cromito de lantânio e de composições com diferentes tipos e teores de elementos dopantes.

\section{Estrutura cristalina}

$\mathrm{O} \mathrm{LaCrO}_{3}$ apresenta uma estrutura cristalina do tipo perovskita, sendo considerado como pseudo-perovskita ou perovskita distorcida, por não ser perfeitamente cúbica como normalmente ocorre nas demais perovskitas da família $\mathrm{ABO}_{3}$ [1]. Formando-se a partir de $650{ }^{\circ} \mathrm{C}, \mathrm{o} \mathrm{LaCrO}_{3}$ apresenta célula unitária do tipo ortorrômbica (Pnma), ocorrendo uma transformação alotrópica para a estrutura romboédrica (R3c) durante o aquecimento no intervalo de temperatura entre 240 e $280^{\circ} \mathrm{C}$, tendo como consequência redução no volume do retículo, principalmente devido à redução de tamanho no octaedro $\mathrm{CrO}_{6}$. [2,3]. Trabalhos existentes [4] sugerem que esta estrutura permanece estável até a temperatura aproximada de $1800{ }^{\circ} \mathrm{C}$, onde ocorre a transformação da estrutura romboédrica para a cúbica $(\mathrm{Pm}-3 \mathrm{~m})[5,6]$. Como as estruturas perovskitas permitem uma gama considerável de possíveis substituições de seus cátions, para o $\mathrm{LaCrO}_{3}$ há vários estudos com os mais diversos elementos adicionados em sua estrutura. Entre eles destacam-se alguns: o $\mathrm{Sr}$, o Ca e 


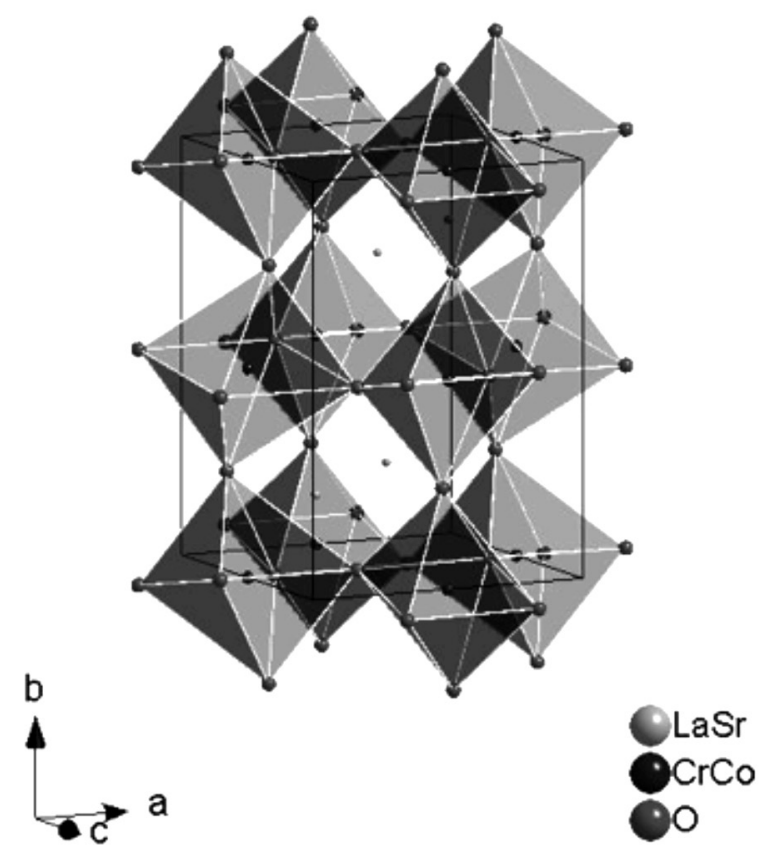

Figura 1: Célula unitária ortorrômbica do cromito de lantânio dopado com estrôncio e cobalto [14].

[Figure 1: Strontium and cobalt doped-lanthanum chromite orthorhombic unit cell.]

também o Ba, devido aos seus raios iônicos e características de carga, substituem com certa facilidade o cátion La. Por outro lado, Mg, Co, Zn, Ni, Fe, AI e Ti são os mais estudados para substituírem o cátion $\mathrm{Cr}$ na estrutura. De acordo com as concentrações utilizadas, estas substituições irão alterar a estrutura deste material influenciando as suas características, tais como: as temperaturas de transformações de fase, a condutividade e expansão térmicas e, também, a condutividade elétrica. Foi observado que a substituição do La por Sr na concentração de 5 mol\% reduz a temperatura de transformação ortorrômbica-romboédrica de $260{ }^{\circ} \mathrm{C}$ para $57{ }^{\circ} \mathrm{C}$ e quando a concentração chega a $15 \%$ (mol) esta temperatura torna-se inferior a $25^{\circ} \mathrm{C}$ [7]. Esta redução na temperatura de transformação de fase, entretanto, não é tão acentuada quando o material dopado com Sr deixa de ser estequiométrico. Mathews [8] determinou para uma concentração de $\mathrm{Sr}$ de $5 \%$ (mol) que a transformação ortorrômbica-romboédrica ocorre entre 230 e $270{ }^{\circ} \mathrm{C}$ e, este intervalo decresce até $100-130{ }^{\circ} \mathrm{C}$ quando a concentração é de $10 \mathrm{~mol} \%$, a partir da qual novos incrementos na concentração de Sr não causam mais nenhuma modificação.

A substituição do La por $\mathrm{Nd}$ eleva a temperatura de transformação de fase. Adições de 5 mol\% $\mathrm{Nd}$ elevam esta temperatura de transformação para o intervalo entre 350-400 ${ }^{\circ} \mathrm{C}$. O aumento da concentração de $\mathrm{Nd}$ adicionado para 25 mol\% leva a um aumento da temperatura de transição para valores da ordem de $750{ }^{\circ} \mathrm{C}$ [8]. Por outro lado, substituições de $\mathrm{Cr}$ por Ni também elevam a temperatura de transformação até $350{ }^{\circ} \mathrm{C}$ quando a concentração de $\mathrm{Ni}$ atinge $20 \mathrm{~mol} \%$. A partir deste teor a temperatura de transformação volta gradualmente a baixar, tal que para uma concentração de 60 mol\% de Ni atinja $89{ }^{\circ} \mathrm{C}$ [9]. Na presença simultânea de Ca e Ti no $\mathrm{LaCrO}_{3}$, dependendo da relação de cátions existentes, pode existir uma solução sólida, de estrutura ortorrômbica, na forma $\mathrm{La}_{\left(1-x^{\prime}-y\right)} \mathrm{Ca}_{\left(x^{\prime}-y\right)} \mathrm{Cr}^{\mathrm{IV}}{ }_{x^{\prime}} \mathrm{Cr}^{\mathrm{III}}{ }_{\left(1-\mathrm{x}^{\prime}-\mathrm{y}\right)} \mathrm{Ti}_{\mathrm{y}} \mathrm{O}_{3}\left(0 \leq \mathrm{x}^{\prime}<0,6-0,7 ; \mathrm{x} \leq\right.$ $\mathrm{y}=0)$ [10]. A substituição de $\mathrm{La}^{3+}$ por $\mathrm{Sr}^{2+}$, que possui maior raio iônico $\left(\mathrm{Sr}^{2+}=0,144 \mathrm{~nm}, \mathrm{La}^{3+}=0,136 \mathrm{~nm}\right)$, deveria levar à tendência natural de ocasionar uma distorção no retículo cristalino, aumentando desta forma o volume da célula unitária. Entretanto, isso não é observado. A compensação de carga na estrutura do $\mathrm{LaCrO}_{3}$, pela adição do $\mathrm{Sr}^{2+}$, ocorre pela oxidação do $\mathrm{Cr}^{3+}(0,055 \mathrm{~nm})$ a $\mathrm{Cr}^{6+}$, que possui raio iônico inferior $\left(\mathrm{Cr}^{6+}=0,044 \mathrm{~nm}\right)$, acarreta a redução do volume final da célula unitária [11]. O mesmo comportamento é observado quando se adiciona Ca [12]. Substituições do cromo por cobalto na estrutura $\mathrm{ABO}_{3}$ reduzem o volume da célula unitária em 1,5\%, até concentrações de $30 \mathrm{~mol} \%$ de cobalto; concentrações maiores levam à transformação ortorrômbicaromboédrica [13]. O aspecto da estrutura ortorrômbica do cromito de lantânio dopado com estrôncio e cobalto é apresentado na Fig.1 [14].

Atualmente, a adição de dopantes vem sendo revisada uma vez que eles podem interferir, significativamente, na estabilidade e no desempenho do cromito de lantânio em condições equivalentes às de operação das células a combustível $[15,16]$.

\section{Condutividade eletrônica}

Uma das características mais importantes do $\mathrm{LaCrO}_{3}$ é sua condutividade elétrica do tipo $\mathrm{p}$ em condições oxidantes e relativa estabilidade em condições redutoras $[17,18]$. A condutividade decresce com a redução na pressão parcial de oxigênio e o $\mathrm{LaCrO}_{3}$ torna-se deficiente em oxigênio $\left(\mathrm{LaCrO}_{3-\delta}\right)$. Desta forma, vazios eletrônicos são consumidos por meio da formação de vacâncias de oxigênio. A condutividade do $\mathrm{LaCrO}_{3}$ puro $\left(1 \mathrm{~S} . \mathrm{cm}^{-1}\right)$ é o mínimo suficiente para utilização como interconectores [19]. Entretanto, para incrementar esta propriedade, fazse necessário adicionar dopantes [20]. Estes dopantes são geralmente elementos alcalinos terrosos, os quais atuam como receptores eletrônicos nas posições dos íons trivalentes lantânio e cromo, e assim aumentam a condução tipo-p por mecanismos de polarização. Os elementos comumente utilizados para este fim são o estrôncio e o cálcio, que quando adicionados ocupam a posição do lantânio e magnésio que, devido a seu raio iônico, substitui na estrutura o cromo [21]. Porém, a condutividade esperada do $\mathrm{LaCrO}_{3}$ quando dopado com $\mathrm{Mg}$, é inferior às condutividades obtidas quando dopado com elementos alcalinos terrosos [22]. A condutividade elétrica do cromito de lantânio dopado com $\mathrm{Sr}$ ou Ca apresenta valores próximos, sendo levemente aumentada na presença de $\mathrm{Ca}$ quando suas concentrações são elevadas [23]. Uma explicação para a maior condutividade nas composições contendo Ca é o seu raio iônico $\left(\mathrm{Ca}^{2+}=0,134 \mathrm{~nm}\right)$ mais próximo ao raio do íon substituído, $\mathrm{La}^{3+}(0,136 \mathrm{~nm})$ do que o $\mathrm{Sr}^{2+}(0,144 \mathrm{~nm})$. Uma menor distorção no retículo cristalino pode resultar em alta mobilidade, e assim elevar 
a condutividade para uma mesma concentração de defeitos [24]. A condutividade eletrônica no $\mathrm{LaCrO}_{3}$ puro ocorre por mecanismos de polarização via transporte de vacâncias eletrônicas, existentes na banda de valência do orbital $3 \mathrm{~d}$ dos íons cromo. Aequação A descreve a reação de condutividade.

$$
3 / 2 \mathrm{O}_{2} \leftrightarrow \mathrm{V}_{\mathrm{La}}^{\prime \prime \prime}+\mathrm{V}_{\mathrm{Cr}}^{\prime \prime \prime}+3 \mathrm{O}_{\mathrm{O}}^{\mathrm{x}}+6 \mathrm{~h}^{\circ}
$$

na qual $\mathrm{V}_{\mathrm{La}}$ "” e $\mathrm{V}_{\mathrm{Cr}}$ " ' referem-se às vacâncias de $\mathrm{La}$ e $\mathrm{Cr}$ respectivamente, $\mathrm{O}_{\mathrm{O}} \mathrm{x}$ é a posição do oxigênio e $\mathrm{h}^{\circ}$ é o vazio eletrônico.

Sob condições oxidantes, a substituição do $\mathrm{La}$ ou do $\mathrm{Cr}$ na estrutura do $\mathrm{LaCrO}_{3}$ por íons de menor valência, resulta em uma compensação de carga pela transição dos íons $\mathrm{Cr}^{3+}$ para $\mathrm{Cr}^{4+}[5,23]$. A condição de neutralidade pode ser descrita da seguinte forma (equação B):

$$
\left[\mathrm{M}_{\mathrm{LA}}{ }^{\prime}\right] \text { ou }\left[\mathrm{N}^{\prime}{ }_{\mathrm{Cr}}\right]=\left[\mathrm{Cr}_{\mathrm{Cr}}{ }^{\circ}\right]
$$

na qual $\mathrm{M}$ refere-se a $\mathrm{Sr}$ ou $\mathrm{Ca}, \mathrm{N}$ representa $\mathrm{Mg}, \mathrm{Fe}, \mathrm{Ni}$, $\mathrm{Cu}$ ou Co, [ ] indica concentração, $\mathrm{Cr}_{\mathrm{Cr}}{ }^{\circ}$ é $\mathrm{Cr}^{4+}$, pela notação Kröger-Vink. O transporte eletrônico no $\mathrm{LaCrO}_{3}$ dopado é controlado por uma baixa polarização em função da carga carregada localizada nas posições Cr. Nestas situações, as notações $\mathrm{h}^{\circ}$ e $\mathrm{Cr}_{\mathrm{Cr}}{ }^{\circ}$ tem o mesmo significado.

A pressão parcial de oxigênio exerce forte influência na condutividade eletrônica. Em baixos níveis de atividade de oxigênio o mecanismo dominante é a compensação iônica através da formação de vacâncias de oxigênio.

Em regimes de baixa atividade de oxigênio, o equilíbrio entre defeitos de espécies e a atmosfera é expresso pela equação C.

$$
1 / 2 \mathrm{O}_{2}+\mathrm{V}_{\mathrm{O}^{\circ}}{ }^{\mathrm{oo}}+2 \mathrm{Cr}_{\mathrm{Cr}}^{\mathrm{x}} \leftrightarrow \mathrm{O}_{\mathrm{O}}^{\mathrm{x}}+2 \mathrm{Cr}_{\mathrm{Cr}}^{\circ}
$$

na qual $\mathrm{Cr}_{\mathrm{Cr}}{ }^{\mathrm{X}}$ representa a posição $\mathrm{Cr}$ e $\mathrm{V}_{\mathrm{O}}{ }^{\circ 0}$ é a vacância oxigênio. Para manter a neutralidade do cristal, a equação (D) considerada é:

$$
\left[\mathrm{M}^{\prime}{ }_{\mathrm{LA}}\right] \text { ou }\left[\mathrm{N}^{\prime}{ }_{\mathrm{Cr}}\right]=2\left[\mathrm{~V}_{\mathrm{O}}^{\mathrm{oo}}\right]+\left[\mathrm{Cr}_{\mathrm{Cr}}{ }^{\circ}\right]
$$

Isto significa que sob condições redutoras a posição do oxigênio transforma-se em vacância de oxigênio com dupla carga, consumindo dois vazios eletrônicos simultaneamente. Ou seja, o desequilíbrio de carga causado pela introdução de dopantes aliovalentes (íons com valência diferentes aos íons da matriz - $\mathrm{La}^{3+} \mathrm{e} \mathrm{Cr}^{3+}$ ) é compensado pela formação de vacâncias de oxigênio em condições redutoras.

Para $\mathrm{LaCrO}_{3}$ dopado com Sr, por exemplo, a estrutura deve ser expressa com $\mathrm{La}_{1-\mathrm{X}} \mathrm{Sr}_{\mathrm{X}} \mathrm{CrO}_{3-\delta}$ devido a presença de vacâncias de oxigênio e dessa maneira, deve ser representada conforme a equação E:

$$
\left[\mathrm{Sr}_{\mathrm{LA}}{ }^{\prime}\right]=2\left[\mathrm{~V}_{\mathrm{O}}^{\mathrm{oo}}\right]+\left[\mathrm{Cr}_{\mathrm{Cr}}{ }^{\circ}\right]
$$

Em condições de atmosfera oxidante (oxigênio ou ar), no cátodo, onde a pressão parcial de oxigênio é relativamente maior $\left(10^{-0,7}\right.$ a $\left.10^{-4} \mathrm{~atm}\right)$, a condutividade é aumentada pela indução da transição $\mathrm{Cr}^{3+}$ para $\mathrm{Cr}^{4+}$, via mecanismo de compensação eletrônica. Por outro lado, em atmosferas redutoras, como dos combustíveis do lado do ânodo, onde a pressão parcial de oxigênio é menor $\left(10^{-8}\right.$ a $10^{-18}$ atm), a condutividade é inferior devido ao aparecimento de vacâncias de oxigênio via mecanismo iônico de compensação. Devido a forte dependência da pressão parcial de oxigênio na condutividade elétrica do $\mathrm{LaCrO}_{3}$ dopado, seus valores em atmosferas redutoras como em hidrogênio são significativamente menores que em atmosfera de ar ou oxidante.

Apesar da diferença nos valores de condutividade elétrica, nas duas atmosferas ao qual o interconector fica submetido durante a operação das SOFCs, quando dopado o $\mathrm{LaCrO}_{3}$ torna-se adequado para utilização em temperaturas acima de $800{ }^{\circ} \mathrm{C}$. Entretanto, abaixo desta temperatura, a condutividade do $\mathrm{LaCrO}_{3}$ para utilização como interconectores não é satisfatória [25]. Adições de Sr, entretanto, devem ser limitadas a valores até $30 \%$ em mol, que, por possuir baixa solubilidade na estrutura do $\mathrm{LaCrO}_{3}$, tende à formação de fases secundárias que reduzem a condutividade elétrica. Contudo, durante a operação apresenta-se mais estável do que composições contendo Ca, que é um aditivo com função similar [26-29]. A mistura de 5 \% em massa de $\mathrm{Sm}_{0,2} \mathrm{Ce}_{0,8} \mathrm{O}_{1,9}$ à composição $\mathrm{La}_{0,7} \mathrm{Ca}_{0,3} \mathrm{CrO}_{3-\delta}$, eleva a condutividade eletrônica do material de 17,77 a 687,81 S.cm $^{-1}$ a $800{ }^{\circ}$ C. Porém, suas adições elevam os valores do coeficiente de expansão térmica (CET) em relação aos demais componentes das SOFC [30]. A adição simultânea de $\mathrm{Sr}$ e Co na estrutura do cromito de lantânio promove a formação de $\mathrm{Cr}^{4+} \mathrm{e} \mathrm{Co}^{4+}$ para manter o equilíbrio de cargas, acarretando na diminuição da energia de ativação para a condução e, sob atmosfera de hidrogênio, vacâncias de oxigênio são formadas e a condutividade elétrica diminui como resultado da compensação iônica [31].

Alguns valores de condutividade elétrica, com as respectivas temperaturas de medida, para diversas composições de cromito de lantânio, são apresentados na Tabela I. Como se observa nesta tabela, a condutividade elétrica do cromito de lantânio é marcadamente influenciada pelo tipo e concentração de dopantes utilizados. Quando se

Tabela I - Condutividade elétrica de composições de $\mathrm{LaCrO}_{3}$ [25].

[Table I - Electrical conductivity of $\mathrm{LaCrO}_{3}$ compositions.]

\begin{tabular}{lcc}
\hline \multicolumn{1}{c}{ Composição } & $\begin{array}{c}\text { Condutividade } \\
\left(\mathrm{S} . c m^{-1}\right)\end{array}$ & $\begin{array}{c}\text { Temperatura } \\
\left({ }^{\circ} \mathrm{C}\right)\end{array}$ \\
\hline $\mathrm{LaCrO}_{3}$ & $0,34-1$ & $700-1000$ \\
$\mathrm{LaCr}_{0,9} \mathrm{Mg}_{0,1} \mathrm{O}_{3}$ & 3 & 1000 \\
$\mathrm{La}_{0,9} \mathrm{Sr}_{0,1} \mathrm{CrO}_{3}$ & 14 & 1000 \\
$\mathrm{La}_{0,95} \mathrm{Ca}_{0,05} \mathrm{CrO}_{3}$ & 2,3 & 700 \\
$\mathrm{La}_{0,7} \mathrm{Sr}_{0,3} \mathrm{Cr}_{0,95} \mathrm{CO}_{0,5} \mathrm{O}_{3}$ & 58 & 700 \\
$\mathrm{La}_{0,95} \mathrm{Ca}_{0,05} \mathrm{Cr}_{0,95} \mathrm{Co}_{0,5} \mathrm{O}_{3}$ & 63 & 700 \\
\hline
\end{tabular}


adiciona somente $\mathrm{Sr}$, o valor de condutividade é superior aos valores com adições de $\mathrm{Ca}$ e $\mathrm{Mg}$. Adições de mais de um elemento promovem ainda maiores valores, em relação às composições contendo somente um elemento. Entretanto, em todas as condições de dopagem, a condutividade elétrica é significativamente maior do que para o $\mathrm{LaCrO}_{3}$ puro. Os valores apresentados variam de 0,34 a $63{\mathrm{~S} . \mathrm{cm}^{-1}}^{-1}$ no intervalo de temperatura de 700 a $1000{ }^{\circ} \mathrm{C}$ e, no caso das SOFCs, os maiores valores de condutividade são os mais adequados.

\section{Expansão térmica e resistência mecânica}

Em geral, o componente utilizado como valor de referência para as SOFC é a 8YSZ (eletrólito) que possui coeficiente de expansão térmica em torno de $10,5 \times 10^{-6}{ }^{\circ} \mathrm{C}^{-1}[5,24]$.

Sob o ponto de vista de comportamento térmico, adições somente de $\mathrm{Co}$ ao $\mathrm{LaCrO}_{3}$, ainda que atinja altos valores de densidade utilizando menores tempos e temperaturas de sinterização, promovem um grande aumento nos valores do coeficiente de expansão térmica (CET). Foi observado que o aumento da concentração de $\mathrm{Co}$ no $\mathrm{LaCrO}_{3}$, está diretamente relacionado com o aumento do valor do CET [24]. Adições de $\mathrm{Ca}$ reduzem os valores de CET e quando, combinadas com Co, conduzem a valores adequados para uso como interconectores, pois aumentam a condutividade elétrica [32] e melhoram a sinterabilidade [33]. Do mesmo modo que ocorre com a condutividade elétrica, o uso de dopantes tais como $\mathrm{Ca}, \mathrm{Sr}$ e $\mathrm{Mg}$ também influenciam nos valores de CET. Quando comparados com os valores medidos para o $\mathrm{LaCrO}_{3}$ puro, por exemplo, para uma mesma concentração de aditivos, o aumento observado no valor do CET para o $\mathrm{Sr}$ é superior aos cátions $\mathrm{Ca}$ e $\mathrm{Mg}$. Por outro lado, a adição de $\mathrm{Mg}$ pouco modifica este valor [34, 35]. A evolução do CET do cromito de lantânio com adição de dopantes diversos é apresentado na Fig. 2.

Basicamente, a única carga mecânica na qual o $\mathrm{LaCrO}_{3}$

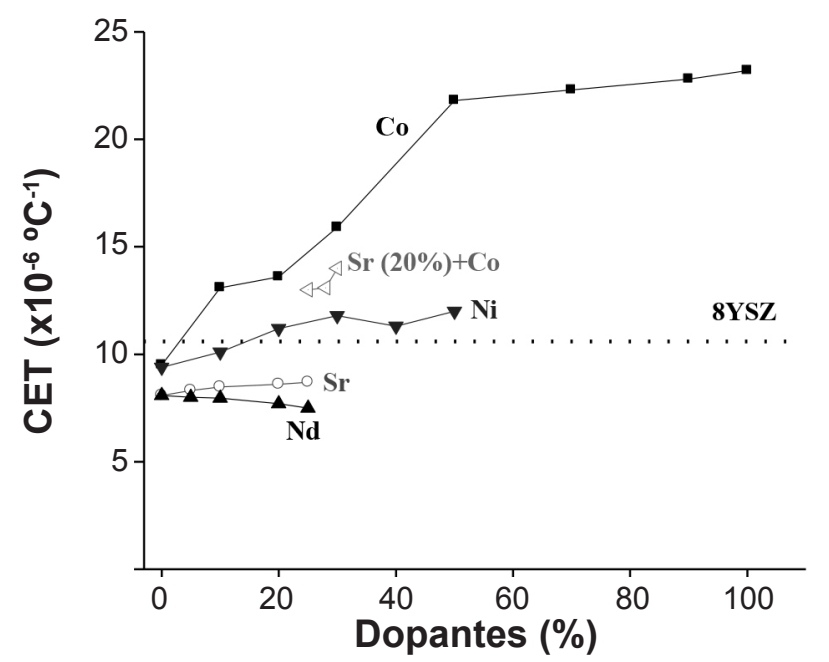

Figura 2: Coeficiente de expansão térmica em função da concentração de dopantes (Co [32], Nd [8], Ni [9], Sr [8] e Sr $(20 \%)+\mathrm{Co}[37])$.

[Figure 2: TEC vs dopant concentration.] fica submetido em operação é o peso da estrutura, que depende da geometria da célula considerada. Quando dopado com $\mathrm{Mg}$, apresenta resistência mecânica em alta temperatura superior $\left(\sim 140 \mathrm{MPa}\right.$ a $\left.1000{ }^{\circ} \mathrm{C}\right)$ aos valores encontrados quando dopado com $\mathrm{Ca}$ e $\mathrm{Sr}(\sim 60 \mathrm{MPa}$ e $\sim$ $30 \mathrm{MPa}$ a $1000{ }^{\circ} \mathrm{C}$, respectivamente). A maior resistência mecânica apresentada pelo cromito dopado com estrôncio se deve principalmente à estabilidade da estrutura romboédrica em alta temperatura. $\mathrm{O}$ desempenho destes materiais sob cargas pode melhorar pelo uso de placas finas e densas [23].

$\mathrm{O}$ módulo de elasticidade no $\mathrm{LaCrO}_{3}$ dopado varia conforme a composição e o estado de oxidação [38]. Para o cromito de lantânio dopado com estrôncio e magnésio o módulo de elasticidade é menor nas composições submetidas à oxidação (255 e $611 \mathrm{GPa}$, respectivamente) do que nas amostras submetidas a redução (361 e 791 $\mathrm{GPa}$, respectivamente). Para composições de cromito de lantânio dopado com cálcio o módulo elástico na amostra oxidada (667 GPa) é levemente maior do que na amostra reduzida (632 $\mathrm{GPa})$, sendo que esta diferença entre ambas as atmosferas, é reduzida na medida em que a concentração de $\mathrm{Ca}$ aumenta. As mudanças no módulo de elasticidade são atribuídas às mudanças nas distâncias interatômicas entre os íons cromo e oxigênio. Com o decréscimo desta distância o módulo de elasticidade é aumentado [39].

A resistência à flexão do cromito de lantânio dopado com cálcio decresce com a temperatura, mesmo em baixas temperaturas, enquanto o $\mathrm{LaCrO}_{3} \mathrm{com}$ adição de estrôncio não mostra nenhuma variação na resistência numa ampla faixa de temperatura. A resistência é reduzida quando o cromito de lantânio é tratado em baixas pressões de oxigênio, em conseqüência das mudanças estruturais nos retículos que acompanham a transição $\mathrm{Cr}^{4+}$ para $\mathrm{Cr}^{3+}$ e formação de vacâncias. Em cromitos de lantânio reduzidos, a fratura se propaga preferencialmente através dos grãos [40].

Composições $\mathrm{La}_{1-\mathrm{X}} \mathrm{Sr}_{\mathrm{x}} \mathrm{Cr}_{1-\mathrm{y}} \mathrm{Co}_{\mathrm{y}} \mathrm{O}_{3}$ apresentaram valores de resistência mecânica e de dureza de $62 \mathrm{MPa}$ e 5,98 GPa, respectivamente [41], e módulo de Weibull, a $1000{ }^{\circ} \mathrm{C}$, de 9,7 , mostrando boa confiabilidade nos resultados [42], com modos de fratura inter e transgranulares para comportamento de deformação frágil [41].

\section{Sinterização}

O cromito de lantânio apresenta baixa densidade quando sinterizado ao ar ou atmosfera oxidante. A baixa densificação do $\mathrm{LaCrO}_{3}$ puro em atmosfera de ar é uma de suas características mais preocupantes para aplicá-lo como interconector em $S O F C$. Atribui-se esta baixa densificação, ao mecanismo predominante na sinterização que é o de evaporação-condensação, onde as espécies de cromo voláteis saem dos grãos na forma de $\mathrm{CrO}_{3}(\mathrm{~g})$ e depositam-se nos pontos de contato entre partículas (pescoços), formando uma fina camada de $\mathrm{Cr}_{2} \mathrm{O}_{3}$ (s) durante o primeiro estágio da sinterização, que inibe o transporte de massa via estado sólido, acarretando baixa remoção de poros ou densificação [43-46] e assim, a sinterização é paralisada neste estágio [5, 
47, 48]. Para inibir a volatilização do cromo e promover a sinterização/densificação do cromito de lantânio é necessário reduzir a pressão parcial de oxigênio do meio e devido a sua baixa difusividade, aumentar a temperatura de sinterização para valores superiores a $1600{ }^{\circ} \mathrm{C}$ [49].

$\mathrm{O}$ processo de sinterização também pode ser promovido diminuindo as concentrações de cromo, ou seja, utilizando-se composições não estequiométricas $[48,50]$. Este comportamento causado pela deficiência do $\mathrm{Cr}$ deve-se possivelmente à formação de vacâncias de cromo que favorecem o processo de difusão por fase sólida com conseqüente densificação. Nos últimos anos, inúmeros estudos têm sido realizados visando o aumento da sinterabilidade do $\mathrm{LaCrO}_{3}$ em temperaturas abaixo de $1600{ }^{\circ} \mathrm{C}$, em atmosfera oxidante. Entre as opções estudadas destacam-se: utilização de pós altamente reativos, variações na estequiometria do material $[43,51]$, uso de dopantes [37, 43, 51-53], aditivos de sinterização, e otimização das técnicas de processamento [37, 43, 54, 55].

O Co é um dos aditivos mais comumente utilizado para auxiliar na densificação do $\mathrm{LaCrO}_{3}$ pois é um elemento totalmente miscível na estrutura do cromito de lantânio e forma o cobaltito de lantânio $\left(\mathrm{LaCoO}_{3}\right)$ que, embora apresente uma estrutura cristalina similar ao cromito de lantânio, possui ponto de fusão relativamente inferior $\left(1400{ }^{\circ} \mathrm{C}\right) \mathrm{LaCrO}_{3}\left(2450{ }^{\circ} \mathrm{C}\right)$ [33]. Este fato faz com que o Co seja um efetivo promotor da sinterização do cromito de lantânio. Entretanto, grandes quantidades de cobalto, podem comprometer o desempenho elétrico característico do cromito de lantânio. Por este motivo, o uso deste aditivo deve ser cuidadosamente quantificado. Composições $\mathrm{LaCr}_{0,7} \mathrm{Co}_{0,3} \mathrm{O}_{3}$ apresentam elevados valores $(99,1 \%)$ de densidade teórica quando sinterizadas a $1500{ }^{\circ} \mathrm{C}$ em ar [56].

A presença simultânea de $\mathrm{Ca}$ e $\mathrm{Co}$, favorece a densificação do $\mathrm{LaCrO}_{3}$ em temperaturas inferiores a $1500{ }^{\circ} \mathrm{C}$. O sistema contendo os dois dopantes, quando na proporção molar de $2(\mathrm{CaO}): 3(\mathrm{CoO})$, produz um eutético em aproximadamente a $1400{ }^{\circ} \mathrm{C}$, promovendo a sinterização pela formação de fase líquida transiente, que contribui para a formação de uma microestrutura final homogênea [33]. Tanto o Ca como o Sr na estrutura do $\mathrm{LaCrO}_{3}$ favorecem a densificação devido a formação, de forma geral, de uma fase líquida transiente durante a sinterização, que se funde em temperaturas próximas de $1050{ }^{\circ} \mathrm{C}$ [57-59] e ao final do processo não deixa fases secundárias [60]. O estágio inicial desta forma de sinterização ocorre entre os dez primeiros minutos após a formação do líquido e, por capilaridade uma mesma concentração de dopantes ( $\mathrm{Ca}$ e $\mathrm{Sr}$ ) adicionados ao $\mathrm{LaCrO}_{3}$, promove o molhamento das partículas com rápida densificação [59]. Foi mostrado que é possível se obter resultados de densidade iguais, mas em temperaturas bem distintas [59]. Enquanto que, para a composição contendo $\mathrm{Ca}$, a temperatura de sinterização utilizada foi de $1400^{\circ} \mathrm{C}$, a composição contendo $\mathrm{Sr}$ precisou de $1700^{\circ} \mathrm{C}$. O mecanismo que explica esta diferença nos valores nas temperaturas de sinterização, porém, não é plenamente compreendido [59].

Adições do óxido $\mathrm{Sm}_{0,2} \mathrm{Ce}_{0,8} \mathrm{O}_{1,9}$ à composição
$\mathrm{La}_{0,7} \mathrm{Ca}_{0,3} \mathrm{CrO}_{3-\delta}$, por meio de mistura mecânica em proporções de até $10 \%$ em massa de $\mathrm{Sm}_{0,2} \mathrm{Ce}_{0,8} \mathrm{O}_{1,9}$, permitem obter valores de densidade relativa após sinterização a $1400{ }^{\circ} \mathrm{C}$ por 4 h de $98 \%$ [30]. A baixa temperatura de sinterização do $\mathrm{LaCrO}_{3}$ dopado com Ca pode ser também explicada pela formação de $\mathrm{Ca}_{\mathrm{m}}\left(\mathrm{CrO}_{4}\right)_{\mathrm{n}}$, que funde incongruentemente e reage com $\mathrm{La}_{1-\mathrm{X}} \mathrm{Ca}_{\mathrm{X}} \mathrm{Cr}_{1-\mathrm{Y}} \mathrm{O}_{3}$ o qual aumenta o transporte de massa resultando em rápida densificação. Cálculos químicos termodinâmicos revelam que a fase líquida oxicromato de cálcio e a fase $\mathrm{La}_{1-\mathrm{X}} \mathrm{Ca}_{\mathrm{X}} \mathrm{Cr}_{1-Y} \mathrm{O}_{3}$ podem coexistir a $1300^{\circ} \mathrm{C}$ se a concentração de $\mathrm{Ca}_{(\mathrm{X})}$ for maior que $50 \mathrm{~mol} \%$ [51].

Em composições $\left(\mathrm{La}_{1-\mathrm{X}} \mathrm{AE}_{\mathrm{X}}\right)_{1+\mathrm{Y}} \mathrm{CrO}_{3}$, onde $\mathrm{AE}$ pode ser $\mathrm{Sr}$ ou $\mathrm{Ca}$, o excesso de $\mathrm{Sr}$ tem um efeito na sinterização muito inferior em relação a um excesso de $\mathrm{Ca}$ [57]. Nas composições contendo $30 \mathrm{~mol} \%$ de $\mathrm{Sr}$, quando há um acréscimo no valor de $\mathrm{Y}$ na composição $\left(\mathrm{La}_{1-\mathrm{X}} \mathrm{Sr}_{\mathrm{X}}\right)_{\mathrm{Y}} \mathrm{CrO}_{3} \mathrm{Ou}$ seja, $\mathrm{Y}>1,0$ o processo de sinterização inicia-se por volta de $1050{ }^{\circ} \mathrm{C}$ atribuído à formação de $\mathrm{SrCrO}_{4}$, apesar de seu ponto de fusão, quando puro, ser de $1253^{\circ} \mathrm{C}$. Esta redução na temperatura em mais de $100{ }^{\circ} \mathrm{C}$, deve-se a dissolução do La na fase $\mathrm{SrCrO}_{4}$ e possivelmente pela interação com outras fases formadas, como a fase $\mathrm{Sr}_{2,67}\left(\mathrm{CrO}_{4}\right)_{2}$. Comportamento idêntico é observado no $\mathrm{LaCrO}_{3}$ dopado com $\mathrm{Ca}$ não estequiométrico. Uma segunda etapa na sinterização é atribuída a fusão da fase $\mathrm{Sr}_{2,67}\left(\mathrm{CrO}_{4}\right)_{2}$ em torno de $1400{ }^{\circ} \mathrm{C}$, formada pela reação de decomposição entre $\mathrm{O} \mathrm{SrCrO}_{4}$ e o $\mathrm{La}_{2} \mathrm{CrO}_{6} \mathrm{e}$, apesar desta fase $\left(\mathrm{Sr}_{2,67}\left(\mathrm{CrO}_{4}\right)_{2}\right)$ apresentar ponto de fusão em $1450{ }^{\circ} \mathrm{C}$, a redução a $1400{ }^{\circ} \mathrm{C}$ é creditada a uma possível interação com outros compostos, como o $\mathrm{La}_{2} \mathrm{O}_{3}$, que reduz a temperatura em $50^{\circ} \mathrm{C}$. Quando $\mathrm{Y}<1,0$ a sinterização ocorre somente pela fusão da fase $\mathrm{SrCrO}_{4} \mathrm{em}$ torno de $1250{ }^{\circ} \mathrm{C}$ [50]. A fase $\mathrm{Sr}_{2,67}\left(\mathrm{CrO}_{4}\right)_{2}$ não é detectada na difração de raios $\mathrm{X}[61,62]$.

Para aumentar o grau de sinterização do $\mathrm{LaCrO}_{3}$ dopado com $\mathrm{Sr}$, foram sugeridas altas temperaturas e altas taxas de aquecimento [16]. O principal problema com a fase líquida transiente é que, em processos de co-sinterização do $\mathrm{LaCrO}_{3}$ com outros componentes da $S O F C$, a fase liquida poderá se difundir para estes componentes causando mudanças em suas propriedades [16]. Adições simultâneas de Sr e Co no cromito de lantânio proporcionam valores de densidade final acima de $90 \%$, desejáveis quando se visa a sua aplicação como interconectores $[37,63]$.

\section{Aplicações}

Devido às suas características intrínsecas, o cromito de lantânio torna-se adequado para aplicações como interconector em células a combustível de óxido sólido [23, 64-67], geradores magneto hidrodinâmicos (MHD) [6870], catalisadores para queima de combustíveis [71-73], sensores de $\mathrm{NO}_{\mathrm{X}}$ em alta temperatura [74], resistências para fornos [75, 76] e sensor potenciométrico de oxigênio [77]. Ainda na geração de energia, pode ser utilizado como ânodo para células de óxido sólido de temperatura intermediária (ITSOFC) [78-83].

Os geradores magneto hidrodinâmicos $(M H D)$ são 
dispositivos capazes de converter energia térmica ou energia cinética diretamente em eletricidade. São vantajosos em relação aos geradores elétricos tradicionais por não apresentarem partes móveis, pois, para gerar a eletricidade, utiliza a movimentação de um plasma em seu interior. Para que se forme o plasma são necessárias temperaturas superiores a $2000{ }^{\circ} \mathrm{C}$ e, nestas condições, muitos átomos de gás, que se deslocam a grandes velocidades chocam-se entre si com energia suficiente para liberar elétrons e assim deixá-los ionizados. O uso do cromito de lantânio como revestimento interno dos componentes usados para o plasma nos geradores $M H D$ se deve ao fato do $\mathrm{LaCrO}_{3}$ além de suportar as elevadas temperaturas de operação, necessárias para formar e manter o plasma, também coleta e conduz a eletricidade gerada pela movimentação do plasma no sistema.

Nos fornos de temperatura elevada, pode-se utilizar resistências de $\mathrm{LaCrO}_{3}$, pois este apresenta elevado ponto de fusão $\left(\sim 2500{ }^{\circ} \mathrm{C}\right)$, possui resistência química a gases com diferentes pressões parciais de oxigênio e alta condutividade elétrica em meio oxidante, sendo possível atingir temperaturas de operação da ordem de $1800{ }^{\circ} \mathrm{C}$.

Estuda-se o uso de $\mathrm{LaCrO}_{3}$ em sensores de $\mathrm{NO}_{x}$ pois, sendo um condutor eletrônico em temperaturas da ordem de 600$700{ }^{\circ} \mathrm{C}$, é capaz de detectar diferenças de $\mathrm{NO}_{\mathrm{X}}$ no ambiente. Pode substituir integralmente a platina, que é normalmente utilizada, ou então estar associado a ela ou a dispositivos que a contêm, apresentando um custo relativamente menor [74, 84]. Esses motivos são também utilizados para justificar o estudo do cromito de lantânio como eletrodos para sensores potenciométricos de oxigênio [77].

Quando o $\mathrm{LaCrO}_{3}$ é utilizado em catalisadores de fuligens de combustíveis, especifica-se para a redução das emissões particuladas que ocorrem na queima do diesel, uma vez que os motores a diesel operam na faixa de 150 a $400{ }^{\circ} \mathrm{C}$, ou seja, abaixo da temperatura necessária à conversão da fuligem produzida que é em torno de $600{ }^{\circ} \mathrm{C}$. As características do cromito de lantânio que atende a esta aplicação são: alta área de superfície específica e alta atividade catalítica [71-73].

A possibilidade de se utilizar $\mathrm{LaCrO}_{3}$ como ânodo em células do tipo ITSOFC despertou interesse após a sua eficiência catalítica ser comprovada para o gás metano, que é potencialmente um dos combustíveis mais promissores para uso nas células a combustível [78]. A utilização do $\mathrm{LaCrO}_{3}$ como ânodo nas ITSOFC alimentadas com metano, atende aos requisitos de estabilidade na temperatura de operação $\left(\sim 750^{\circ} \mathrm{C}\right)$. Entretanto, neste caso, necessita da adição, por exemplo, de rutênio, para promover a reforma do metano, aumento na resistência à deposição de carbono e também reduzindo a sua densificação, favorecendo a formação de poros necessários à passagem do combustível.

Nas SOFCs, quando utilizado como ânodo, o $\mathrm{LaCrO}_{3}$, atende aos requisitos de estabilidade nas condições de operação, uma boa capacidade catalítica para os combustíveis, em particular o metano, maior tolerância à contaminação superficial por carbono, quando comparado com o cermet Ni-YSZ (niquel-zircônia estabilizada com ítria) que é o ânodo normalmente estudado [81, 82, 85].
Nas SOFCs o interconector é utilizado para promover a conexão elétrica entre o ânodo de uma célula unitária e o cátodo da célula adjacente e, atuar como uma barreira física para os gases envolvidos, evitando desta forma, a mistura do combustível (hidrogênio) do ânodo, com o ar (oxigênio) do cátodo, devendo, portanto, ser denso. Em células a combustível $(\mathrm{CaC})$ de geometria plana, o interconector também pode atuar como suporte para dar estabilidade mecânica ao empilhamento de células (stack) [5, 24, 67].

$\mathrm{O} \mathrm{LaCrO}_{3}$ é atualmente o material existente mais indicado como interconector nas SOFCs e quando dopado, cumpre a maioria de seus requisitos, que são: ter estabilidade em ambientes redutores (ânodo) e oxidantes (cátodo), suportando pressões parciais de oxigênio de $10^{-18}$ a $10^{-0.7}$ atm $[66,86-88]$,

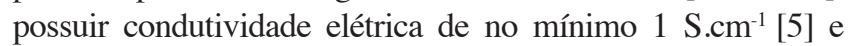
ter valor de coeficiente de expansão térmica (CET) bastante próximo aos dos outros componentes da $\operatorname{SOFC}\left(9,5 \times 10^{-6}{ }^{\circ} \mathrm{C}^{-1}\right)$ na temperatura de operação $\left(>800{ }^{\circ} \mathrm{C}\right)[5,23,66,86,88-90]$.

A função dos dopantes ( $\mathrm{Sr}$ e $\mathrm{Co}$ ) adotados neste trabalho tem o seguinte objetivo: o $\mathrm{Sr}$ é adicionado para melhorar as propriedades elétricas e o Co para melhorar o comportamento de sinterização favorecendo a densificação, além disso, sabese que a adição de Co é o modo mais efetivo de se aumentar o coeficiente de expansão térmica $[5,24,42,52,91]$.

\section{Síntese do cromito de lantânio}

O cromito de lantânio pode ser obtido por muitas rotas de síntese. Uma das rotas tradicionais utilizadas é a mistura de óxidos, ou síntese em estado sólido e, neste caso, os óxidos ou até mesmo carbonatos dos metais, são misturados mecanicamente e, tratados termicamente até a temperatura de formação da fase desejada $[47,51,59,92]$.

A síntese por coprecipitação, do cromito de lantânio, pode ser realizada a partir de carbonatos e óxidos em solução de acido nítrico e oxálico. Na síntese por coprecipitação há a necessidade de tratamento térmico posterior para obtenção da fase óxido desejada, bem como para eliminação dos compostos orgânicos presentes [93].

A obtenção do cromito de lantânio pela rota sol-gel pode ser feita utilizando-se como materiais de partida os respectivos cloretos metálicos dissolvidos em metanol, precipitados com cloreto de amônio e, estabilizados pela adição de ácido hidroclórico e, do mesmo modo que a síntese por coprecipitação, o material obtido necessita ser calcinado [94, 95].

$\mathrm{O}$ processo de obtenção do $\mathrm{LaCrO}_{3}$ via método hidrotermal, utiliza uma solução aquosa que pode ser de nitrato ou acetato em uma autoclave, entretanto o produto não é produzido diretamente, assim como os métodos de síntese anteriores, esta técnica necessita de uma posterior calcinação para obtenção da fase desejada [96-98].

Pelo método Pechini, o $\mathrm{LaCrO}_{3}$ também pode ser produzido e, para isto utiliza como reagentes uma solução aquosa de nitrato dos seus metais misturados com de ácido cítrico $[63,99,100]$. Outro método empregado na síntese do cromito de lantânio, chamado de método de resina 
intermediária, consiste no método Pechini modificado. Para esta técnica de síntese uma solução aquosa dos nitratos metálicos é misturada ao ácido cítrico e ao etileno glicol, são aquecidos até evaporação da água e formação do gel e este é, calcinado até a obtenção do produto final e eliminação de orgânicos [101].

Entre as diversas rotas de síntese utilizadas para a obtenção do $\mathrm{LaCrO}_{3}$, a reação de combustão mostra-se uma opção interessante por resultar em pós com boa homogeneidade química e tamanho de partículas de ordem nanométrica, em um tempo curto [102]. Parte de uma mistura de reagentes oxidantes (nitratos, sulfatos, carbonatos, entre outros) e um combustível orgânico (uréia, carboidrazina, hidrazina maleica, etc.), que age como reagente redutor. A solução com a mistura é aquecida até a ebulição seguida de autoignição, ocorrendo uma reação rápida e autossustentável [103]. Os trabalhos que utilizaram a reação de combustão na obtenção do cromito de lantânio utilizaram em sua maioria o sistema reacional nitrato/uréia [14, 104-106]. Comparando a rota de síntese por combustão com as técnicas de mistura de óxidos e Pechini, foi observado que os pós obtidos por combustão apresentam maior sinterabilidade do que os pós obtidos pelas outras técnicas [104]. Vários pesquisadores utilizaram meios reacionais distintos na síntese por reação de combustão para se obter o cromito de lantânio dopado, destacando-se os trabalhos das referências [40, 61, 62, 107, 108-114].

Uma das técnicas utilizadas na obtenção do $\mathrm{LaCrO}_{3}$, chamada de complexo precursor, consiste na técnica de reação por combustão porém com tratamento térmico gradual. Toda a água do sistema é evaporada, em baixa temperatura $\left(110^{\circ} \mathrm{C}\right)$ até o ponto de gel, onde é então submetido à calcinação [115], este método de obtenção é muito semelhante ao método da hidrazina, diferindo, porém nos reagentes empregados [116]. O cromito de lantânio pode ainda ser obtido por spray pirólise [117].

\section{Química de superfície}

No preparo de suspensões aquosas adequadas, para as mais diversas técnicas de conformação, o comportamento coloidal e as transformações interfaciais existentes do cromito de lantânio quando em meio aquoso devem ser considerados, e variam significativamente em função

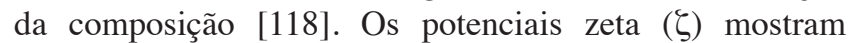
isoeletricidade em distintos valores e, os valores máximos de mobilidade não variam em função das espécies presentes nas suspensões, atingindo valores máximos em pH 3,0. Por outro lado, a redução de mobilidade eletroforética para $\mathrm{pH}$ inferiores a 3,0 é justificada pela dissolução do cromo superficial com o aumento da força iônica [119]. Os valores de $\mathrm{pH}$ onde ocorre a isoeletricidade, identificados para as diversas composições de cromito de lantânio, são apresentados na Tabela II.

O comportamento superficial, valores de potencial zeta e ponto isoelétrico, não se alteram com o tamanho das partículas [14, 124], conforme apresentado na Fig. 3 . Os menores valores de estabilidade na região alcalina são
Tabela II - Ponto isoelétrico para distintas composições de cromito de lantânio.

[Table II - Isoelectric point for some lanthanum chromite compositions.]

\begin{tabular}{lcc}
\hline Composição & $\mathrm{pH}_{\text {PIE }}$ & Referência \\
\hline $\mathrm{La}_{0,8} \mathrm{Ca}_{0,2} \mathrm{CrO}_{2,9}$ & 5,6 & {$[120]$} \\
$\mathrm{LaCr}_{0,9} \mathrm{Zn}_{0,1} \mathrm{O}_{2,95}$ & 7,6 & {$[120]$} \\
$\mathrm{La}_{0,85} \mathrm{Ca}_{0,15} \mathrm{CrO}_{2,93}$ & 6,8 & {$[118]$} \\
$\mathrm{LaCr}_{0,9} \mathrm{Ni}_{0,1} \mathrm{O}_{2,95}$ & 7,6 & {$[118]$} \\
$\mathrm{La}_{0,9} \mathrm{Sr}_{0,1} \mathrm{Cr}_{0,9} \mathrm{Ni}_{0,1} \mathrm{O}_{2,9}$ & 4,1 & {$[118]$} \\
$\mathrm{La}_{0,9} \mathrm{Sr}_{0,1} \mathrm{Cr}_{0,9} \mathrm{Cu}_{0,1} \mathrm{O}_{2,9}$ & 3,7 & {$[118]$} \\
$\mathrm{La}_{0,9} \mathrm{Sr}_{0,1} \mathrm{Cr}_{0,9} \mathrm{Mg}_{0,1} \mathrm{O}_{2,9}$ & 3,7 & {$[118]$} \\
$\mathrm{La}_{0,6} \mathrm{Sr}_{0,4} \mathrm{CoO}_{3}$ & 5,6 & {$[121]$} \\
$\mathrm{La}_{0,8} \mathrm{Sr}_{0,2} \mathrm{Cr}_{0,92} \mathrm{Co}_{0,08} \mathrm{O}_{3}$ & 8,0 & {$[15,122,123]$} \\
\hline
\end{tabular}

atribuídos à formação de complexos de cromo, dissolvidos no meio, que reduzem a mobilidade das partículas [125].

Compostos de óxidos mistos, como o cromito de lantânio, geralmente possuem alguma solubilidade em meio aquoso onde os valores de $\mathrm{pH}$, determinam as espécies formadas [126]. A solubilidade destes materiais faz com que a dispersão em água seja dificultada e a presença em excesso de íons na suspensão promove um significativo aumento na viscosidade do sistema, acarretando em defeitos nos produtos conformados a verde e consequentemente sinterizados [127]. O cromito de lantânio é atacado superficialmente em meio aquoso, para todo as condições de $\mathrm{pH}$ (2-12), sendo menor $\mathrm{o}$ ataque quando em meio alcalino [122]. A melhor maneira de se produzir suspensões aquosas de cromito de lantânio é em meio alcalino $(\mathrm{pH}>7)$ utilizando-se de polieletrólito aniônico [122, 128].

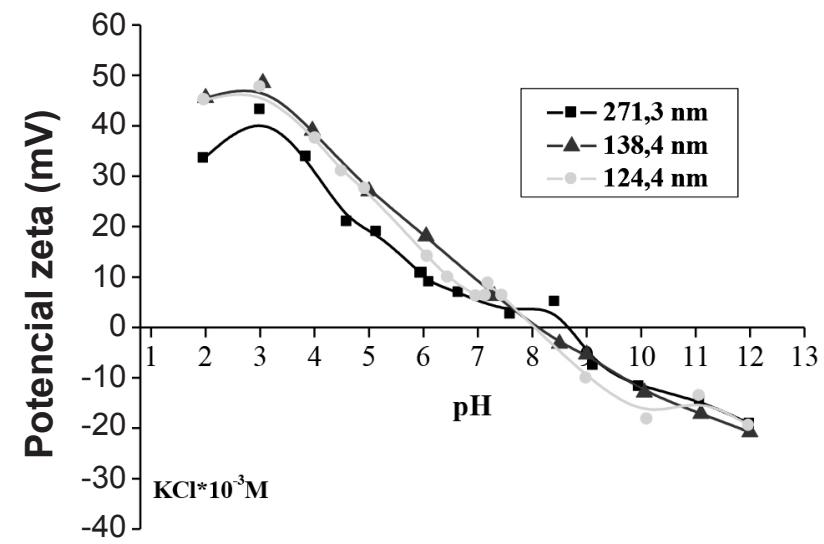

Figura 3: Valores do potencial zeta em função do $\mathrm{pH}$ para diferentes tamanhos de partículas [14].

[Figure 3: Zeta potential values as a function of $\mathrm{pH}$ for different particle sizes.]

Colagem em moldes porosos (slip casting)

O processo de colagem em moldes porosos envolvendo 
a composição $\mathrm{La}_{0,8} \mathrm{Sr}_{02} \mathrm{CrO}_{3}$ foi estudado em uma grande variedade de solventes, todos não aquosos [129]. Após conformação e sinterização em $1600{ }^{\circ} \mathrm{C} / 5 \mathrm{~h}$ o produto com melhor característica, apresentou densidade teórica > $96 \%$. Utilizando-se água como meio dispersor na preparação de suspensões estáveis [122] para conformação em moldes porosos, é possível a obtenção de peças, de cromito de lantânio dopado com estrôncio e cobalto, com densidade $>98,9 \%$ da densidade teórica após sinterização a $1600{ }^{\circ} \mathrm{C} / 4$ h $[128,130]$.

\section{Conformação em fita (tape casting)}

Os estudos sobre o sistema cromito de lantânioaditivos- conformados por colagem de fita, reportados na literatura, são recentes. Fitas de $\mathrm{La}_{0,8} \mathrm{Sr}_{0,2} \mathrm{CrO}_{3}$, após sinterização, apresentaram densidades finais relativas elevadas $(93,5 \%)$ [16]. Foi realizado um criterioso e amplo estudo de conformação por colagem de fita envolvendo distintas condições de preparação de suspensões em meios orgânicos, sem entretanto conseguir obter peças finais livres de defeitos [131]. Fitas de $\mathrm{La}_{0,80} \mathrm{Sr}_{0,20} \mathrm{Cr}_{0,92} \mathrm{Co}_{0,08} \mathrm{O}_{3}$ produzidas utilizando-se suspensões preparadas em etanol após sinterização a $1600{ }^{\circ} \mathrm{C} / 4 \mathrm{~h}$ apresentaram-se com densidades finais superiores a $94 \%$ e, portanto, adequadas para utilização como interconectores em SOFC [132]. Na Fig. 4, é apresentado o aspecto de uma fita de cromito de lantânio conformada por colagem de fita.

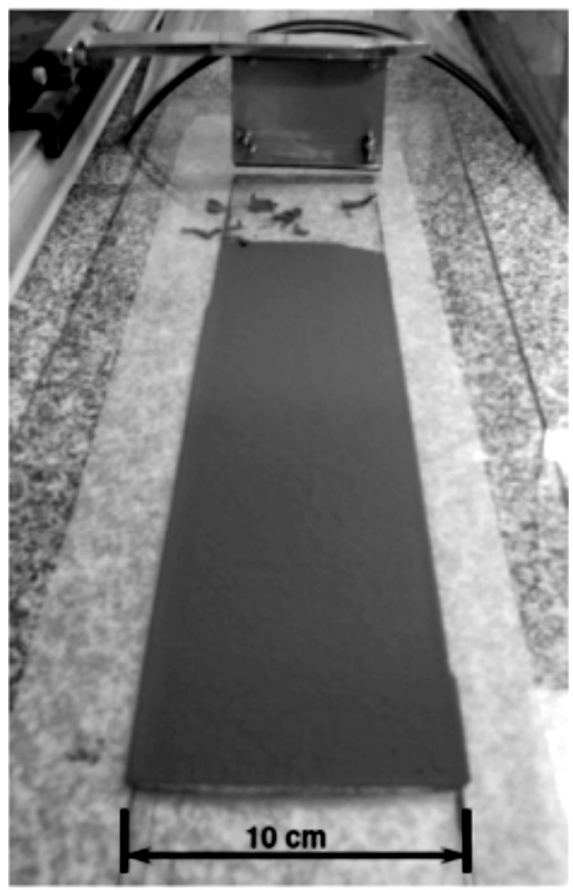

Figura 4: Fita de $\mathrm{LaCrO}_{3}$ conformado pela técnica de colagem de fita [132].

[Figure 4: $\mathrm{LaCrO}_{3}$ tape shaped by tape casting.]

\section{CONSIDERAÇÕES FINAIS}

Atualmente, os estudos para fabricação de elementos interconectores em células a combustível de óxido sólido estão sendo direcionados aos materiais metálicos (superligas de alta temperatura e aços inoxidáveis), uma vez que estes últimos apresentam como vantagens: elevada condutividade elétrica e térmica, facilidade de fabricação e resistência mecânica, em relação ao cromito de lantânio dopado. Porém, sua utilização torna-se muito limitada nas temperaturas de operação das SOFCs, ou seja, acima de $800{ }^{\circ} \mathrm{C}$, devido principalmente aos fenômenos relacionados à oxidação. Desta forma, conforme apresentado neste trabalho, o cromito de lantânio ainda se mostra o material mais adequado para aplicação como interconector em SOFCs [133, 134].

\section{AGRADECIMENTOS}

Os autores agradecem à FAPESP, Procs. 2009/54851-6 e 2013/09329-5, ao CNPq e à CAPES.

\section{REFERÊNCIAS}

[1] A. S. Bhalla, R. Guo, R. Roy, Mater. Res. Innov. 4 (2000) 3-26.

[2] A. E. Gobichon, J. P. Auffrédic, D. Louër, Powder Diffr. 15 (2000) 23-25.

[3] T. Hashimoto, N. Matsushita, Y. Murakami, N. Kojima, K. Yoshida, H. Tagawa, M. Dokiya, T. Kikegawa, Solid State Comm. 108 (1998) 691-694.

[4] S. Geller, P. M. Raccah, Phys. Rev. B 2 (1970) 1167.

[5] N. Q. Minh, J. Am. Ceram. Soc. 76 (1993) 563-588.

[6] K. Oikawa, T. Kamiyama, T. Hashimoto, Y. Shimojyo, Y. Morii, J. Solid State Chem. 154 (2000) 524-529.

[7] T. R. Armstrong, J. S. Hardy, S. P. Simner, J. W. Stevenson,. in: Solid oxide fuel cells (SOFC VI), Proc. Sixth Int. Symp., S. C. Singhal, M. Dokia (Eds.), The Electrochemical Society, Japan (1999) 706-715.

[8] M. D. Mathews, B. R. Ambekar, A. K. Tyagi, Thermochim. Acta 390 (2002) 61-66.

[9] H. E. Höfer, W. F. Kock, J.Electrochem. Soc. 140 (1993) 2889-2894.

[10] V. Vashook, J. Zosel, W. Preis, W. Sitte, U. Guth, Solid State Ionics 175 (2004) 441-444.

[11] X. Liu, W. Su, Z. Lu, J. Liu, L. Pei, W. Liu, L. He, J. Alloy. Compd. 305 (2000) 21-23.

[12] X. Liu, W. Su, Z. Lu, J. Phys. Chem. Solids 62 (2001) 1919-1921.

[13] H. P. S. Corrêa, C. O. Paiva-Santos, L. F. Setz, L. G. Martinez, S. R. H. Mello-Castanho, M. T. D. Orlando, Powder Diffr. 23 (2008) S18-S22.

[14] L. F. G. Setz, S. R. H. Mello-Castanho, R. Moreno, M. T. Colomer, Int. J. Appl. Ceram. Technol. 6 (2009) 626-635. [15] L. A. Chick, J. Liu, J. W. Stevenson, T. R. Armstrong, D. E. McCready, G. D. Maupin, G. W. Coffey, C. A. Coyle, J. Am. Ceram. Soc. 80 (1997) 2109-2120.

[16] L. W. Tai, P. A. Lessing, J. Am. Ceram. Soc. 74 (1991) 155-160.

[17] T. Akashi, T. Maruyama, T. Goto, Solid State Ionics 164 (2003) 177-183. 
[18] T. Nakamura, G. Petzow, L. J. Gauckler, Mater. Res. Bull. 14 (1979) 649-659.

[19] N. Q. Minh, C. R. Horne, F. S. Liu, M. Moffatt, R. R. Staszak, T. L. Stillwagon, J. J. Van Ackeren, "Fabrication and Characterization of Monolithic Solid Oxide Fuel Cells", $25^{\text {th }}$ Energy Conversion Eng. Conf. - IECEC-90, Am. Inst. Chem. Eng., New York, EUA (1990) 230-234.

[20] W. Vielstich, A. Lamm, H. A. Gasteiger, Handbook of Fuel Cells: Fundamentals, Technology, Applications, $2^{\text {nd }}$ ed., John Wiley \& Sons (2003).

[21] B. F. Flandermeyer, M. M. Nasrallah, D. M. Sparlin, H. U. Anderson, High Temp. Sci. 20 (1985) 259-269.

[22] I. Yasuda, M. Hishinuma, Solid State Ionics 80 (1995) 141-150.

[23] J. W. Fergus, Solid State Ionics 171 (2004) 1-15.

[24] W. Z. Zhu, S. C. Deevi, Mater. Sci. Eng. A 348 (2003) 227-243.

[25] N. Q. Minh, T. Takahashi, Science and Technology of Ceramic Fuel Cells, $1^{\text {st }}$ ed., Elsevier Science \& Technology, Amsterdam, Holanda (1995)

[26] A. Ianculescu, A. Braileanu, I. Pasuk, M. Zaharescu, J. Therm. Anal. Calorim. 66 (2001) 501-507.

[27] S. Onuma, S. Miyoshi, K. Yashiro, A. Kaimai, K. Kawamura, Y. Nigara, T. Kawada, J. Mizusaki, N. Sakai, H. Yokokawa, J. Solid State Chem. 170 (2003) 68-74.

[28] D. H. Peck, M. Miller, K. Hilpert, Solid State Ionics 123 (1999) 47-57.

[29] D. H. Peck, M. Miller, K. Hilpert, Solid State Ionics 123 (1999) 59-65.

[30] X. Zhou, F. Deng, M. Zhu, G. Meng, X. Q. Liu, Mater. Res. Bull. 42 (2007) 1582-1588.

[31] L. F. G. Setz, I. Santacruz, L. León-Reina, A. G. De la Torre, M. A. G. Aranda, S. R. H. Mello-Castanho, R. Moreno, M. T. Colomer, Ceram. Int. 41 (2015) 1177-1187.

[32] R. Koc, H. U. Anderson, J. Mater. Sci. Lett. 11 (1992) 1191-1192.

[33] M. R. Morelli, B. Derby, R. J. Brook, Cerâmica 277 (1996 ) 603-606.

[34] X. Ding, Y. Liu, L. Gao, L. Guo, J. Alloy. Compd. 425 (2006) 318-322.

[35] M. Mori, T. Yamamoto, H. Itoh, T. Watanabe, J. Mater. Sci. 32 (1997) 2423-2431.

[36] H. E. Höfer, W. F. Kock, J. Electrochem. Soc. 140 (1993) 2889-2894.

[37] L. F. G. Setz, H. P. S. Corrêa, C. Yamagata, S. R. H. Mello-Castanho, Advances in Solid Oxide Fuel Cells III: Ceram. Eng. Sci. Proc., John Wiley \& Sons, Westerville, EUA (2007) 239-252.

[38] D. Y. Ostrovoi, G. A. Gogotsi, S. A. Suvorov, A. P. Shevchik, Refract. Ind. Ceram. 43 (2002) 237-246.

[39] C. S. Montross, J. Eur. Ceram. Soc. 18 (1998) 353-358. [40] S. W. Paulik, S. Baskaran, T. R. Armstrong, J. Mater. Sci. 33 (1998) 2397-2404.

[41] W. Acchar, C. R. C. Sousa, S. R. H. Mello-Castanho, Mater. Sci. Eng. A 550 (2012) 76-79.

[42] N. M. Sammes, R. Ratnaraj, J. Mater. Sci. 30 (1995) 4523-4526.
[43] J. L. Bates, L. A. Chick, W. J. Weber, Solid State Ionics 52 (1992) 235-242.

[44] S. L. Kang, Sintering: Densification, Grain Growth and Microstructure, Elsevier Butterworth-Heinemann, Oxford (2005).

[45] J. S. Reed, Principles of Ceramics Processing, $2^{\text {nd }}$ ed., John Wiley \& Sons, New York (1995).

[46] D. W. Richerson, Modern Ceramic Engineering: Properties, Processing, and Use in Design, $2^{\text {nd }}$ ed., Marcel Dekker (1992).

[47] S. Hayashi, K. Fukaya, H. Saito, J. Mater. Sci. Lett. 7 (1988) 457-458.

[48] H. Yokokawa, N. Sakai, T. Kawada, M. Dokiya, J. Electrochem. Soc. 138 (1991) 1018-1027.

[49] L. Groupp, H. U. Anderson, J. Am. Ceram. Soc. 59 (1976) 449-450.

[50] S. Simner, J. Hardy, J. Stevenson, T. Armstrong, J. Mater. Sci. 34 (1999) 5721-5732.

[51] N. Sakai, T. Kawada, H. Yokokawa, M. Dokiya, I. Kojima, J. Am. Ceram. Soc. 76 (1993) 609-616.

[52] L. F. G. Setz, H. P. S. Corrêa, C. O. Paiva-Santos, S. R. H. Mello-Castanho, Mater. Sci. Forum 530-531 (2006) 671-676.

[53] J. W. Stevenson, P. F. Hallman, T. R. Armstrong, L. A. Chick, J. Am. Ceram. Soc. 78 (1995) 507-512.

[54] M. A. Janney, C. L. Calhoun, H. D. Kimrey, J. Am. Ceram. Soc. 75 (1992) 341-346.

[55] N. Q. Minh, Solid State Ionics 174 (2004) 271-277.

[56] E. S. M. Seo, W. K. Yoshito, V. Ussui, D. R. R. Lazar, S. R. H. Mello Castanho, J. O. A. Paschoal, Mater. Res. 7 (2004) 215-220.

[57] M. Mori, Y. Hiei, N. M. Sammes, Solid State Ionics 123 (1999) 103-111.

[58] M. Mori, Y. Hiei, N. M. Sammes, Solid State Ionics 135 (2000) 743-748.

[59] N. M. Sammes, R. Ratnaraj, M. G. Fee, J. Mater. Sci. 29 (1994) 4319-4324.

[60] A. Chakraborty, R. N. Basu, H. S. Maiti, Mater. Lett. 45 (2000) 162-166.

[61] S. Simner, J. Hardy, J. Stevenson, T. Armstrong, J. Mater. Sci. Lett. 19 (2000) 863-865.

[62] S. P. Simner, J. S. Hardy, J. W. Stevenson, T. R. Armstrong, Solid State Ionics 128 (2000) 53-63.

[63] M. Mori, N. M. Sammes, Solid State Ionics 146 (2002) 301-312.

[64] S. P. Jiang, S. Zhang, Y. D. Zhen, Mater. Sci. Eng. B-Solid 119 (2005) 80-86.

[65] H. Kleinschmager, A. Reich, Z. Naturforsch. A 27 (1972) 363-365.

[66] A. J. Appleby, F. R. Foulkes, Fuel Cell Handbook, Krieger Publ. Co. (1992).

[67] S. P. S. Badwal, Solid State Ionics 143 (2001) 39-46

[68] D. B. Meadowcroft, J. Phys. D: Appl. Phys. 2 (1969) 1225-1233.

[69] N. Sakai, S. Stølen, J. Chem. Thermodyn. 27 (1995) 493-506.

[70] D. B. Meadowcroft, Energ. Convers. 8 (1968) 185-190 
[71] N. Russo, D. Fino, G. Saracco, V. Specchia, J. Catal. 229 (2005) 459-469.

[72] S. Ifrah, A. Kaddouri, P. Gelin, G. Bergeret, Catal. Comm. 8 (2007) 2257-2262.

[73] D. Fino, N. Russo, G. Saracco, V. Specchia, J. Catal. 217 (2003) 367-375.

[74] D. L. West, F. C. Montgomery, T. R. Armstrong, Sensor. Actuat. B-Chem. 106 (2005) 758-765.

[75] S. A. Suvorov, A. P. Shevchik, Refract. Ind. Ceram. 45 (2004) 196-200.

[76] M. A. Andrianov, V. L. Balkevich, V. E. Sotnikov, Refract. Ind. Ceram. 21 (1980) 592-596.

[77] A. Lund, T. Jacobsen, K. V. Hansen, M. B. Mogensen, J. Solid State Electrochem. 16 (2012) 2113-2120.

[78] G. Saracco, G. Scibilia, A. Iannibello, G. Baldi, Appl. Catal. B-Environ. 8 (1996) 229-244.

[79] A. L. Sauvet, J. T. S. Irvine, Solid State Ionics 167 (2004) $1-8$.

[80] J. Sfeir, P. A. Buffat, P. Möckli, N. Xanthopoulos, R. Vasquez, H. Joerg Mathieu, J. Van herle, K. Ravindranathan Thampi, J. Catal. 202 (2001) 229-244.

[81] J. Sfeir, J. Van Herle, A. J. McEvoy, J. Eur. Ceram. Soc. 19 (1999) 897-902.

[82] P. Vernoux, Ionics 3 (1997) 270-276.

[83] A. L. Sauvet, J. Fouletier, F. Gaillard, M. Primet, J. Catal. 209 (2002) 25-34.

[84] D. L. West, F. C. Montgomery, T. R. Armstrong, Sensor. Actuat. B-Chem. 111 (2005) 84-90.

[85] G. Pudmich, B. A. Boukamp, M. Gonzalez-Cuenca, W. Jungen, W. Zipprich, F. Tietz, Solid State Ionics 135 (2000) 433-438.

[86] C. E. Hatchwell, N. M. Sammes, G. A. Tompsett, I. W. M. Brown, J. Eur. Ceram. Soc. 19 (1999) 1697-1703.

[87] T. Yamamoto, H. Itoh, M. Mori, N. Mori, T. Watanabe, N. Imanishi, Y. Takeda, O. Yamamoto, J. Power Sources 61 (1996) 219-222.

[88] H. Kamata, A. Hosaka, J. Mizusaki, H. Tagawa, Mater. Res. Bull. 30 (1995) 679-687.

[89] N. Sakai, H. Yokokawa, T. Horita, K. Yamaji, Int. J. Appl. Ceram. Technol. 1 (2004) 23-30.

[90] X. L. Zhou, J. J. Ma, F. J. Deng, G. Y. Meng, X. Q. Liu, Solid State Ionics 177 (2007) 3461-3466.

[91] M. Mori, Y. Hiei, T. Yamamoto, J. Am. Ceram. Soc. 84 (2001) 781-786.

[92] Q. Zhang, J. Lu, F. Saito, Powder Technol. 122 (2002) 145-149.

[93] M. R. De Guire, S. E. Dorris, R. B. Poeppel, S. Morissette, U. Balachandran, J. Mater. Res. 8 (1993) 2327 2334.

[94] S. Bilger, G. Bla, R. Förthmann, J. Eur. Ceram. Soc. 17 (1997) 1027-1031.

[95] I. Zhigalkina, T. Nikolaeva, Y. Suponitskii, B. Polyak, Glass Ceram. 55 (1998) 182-185.

[96] J. Ovenstone, K. C. Chan, C. B. Ponton, J. Mater. Sci. 37 (2002) 3315-3322.

[97] L. P. Rivas-Vázquez, J. C. Rendón-Angeles, J. L. Rodríguez-Galicia, K. Zhu, K. Yanagisawa, Solid State
Ionics 172 (2004) 389-392.

[98] L. R. Rivas-Vazquez, J. C. Rendon-Angeles, J. L. Rodriguez-Galicia, C. A. Gutierrez-Chavarria, K. J. Zhu, K. Yanagisawa, J. Eur. Ceram. Soc. 26 (2006) 81-88.

[99] E. Suda, B. Pacaud, T. Seguelong, Y. Takeda, Solid State Ionics 151 (2002) 335-341.

[100] G. -Y. Lee, R. -H. Song, J. -H. Kim, D. -H. Peck, T. -H. Lim, Y. -G. Shul, D. -R. Shin, J. Electroceram. 17 (2006) 723-727.

[101] L. W. Tai, P. A. Lessing, J. Mater. Res. 7 (1992) 511 519.

[102] R. G. Chandran, K. C. Patil, Mater. Lett. 12 (1992) 437-441.

[103] S. S. Manoharan, K. C. Patil, J. Solid State Chem. 102 (1993) 267-276.

[104] M. R. Morelli, B. Derby, R. J. Brook, Cerâmica 276 (1996) 435-438.

[105] S. Biamino, C. Badini, J. Eur. Ceram. Soc. 24 (2004) 3021-3034.

[106] E. P. Marinho, A. G. Souza, D. S. de Melo, I. M. G. Santos, D. M. A. Melo, W. J. da Silva, J. Therm. Anal. Cal. 87 (2007) 801-804.

[107] K. Deshpande, A. Mukasyan, A. Varma, J.Am. Ceram. Soc. 86 (2003) 1149-1154.

[108] K. Zupan, D. Kolar, M. Marinsek, J. Power Sources 86 (2000) 417-422.

[109] K. Zupan, M. Marinsek, S. Pejovnik, J. Macek, K. Zore, J. Eur. Ceram. Soc. 24 (2004) 1935-1939.

[110] K. Zupan, S. Pejovnik, J. Maček, Acta Chim. Slov. 48 (2001) 137-145.

[111] Y. -J. Yang, T. -L. Wen, H. Tu, D. -Q. Wang, J. Yang, Solid State Ionics 135 (2000) 475-479.

[112] A. S. Mukasyan, C. Costello, K. P. Sherlock, D. Lafarga, A. Varma, Sep. Purif. Technol. 25 (2001) 117-126.

[113] S. Ghosh, A. Das Sharma, R. N. Basu, H. S. Maiti, Electrochem. Solid State Lett. 9 (2006) A516-A519.

[114] S. Ghosh, A. Das Sharma, R. N. Basu, H.S. Maiti, J. Am. Ceram. Soc. 90 (2007) 3741-3747.

[115] D. Berger, I. Jitaru, N. Stanica, R. Perego, J. Schoonman, J. Mater. Synth. Proces. 9 (2001) 137-142.

[116] K. Azegami, M. Yoshinaka, K. Hirota, O. Yamaguchi, Mater. Res. Bull. 33 (1998) 341-348.

[117] Y. Jiang, J. Gao, M. Liu, Y. Wang, G. Meng, Mater. Lett. 61 (2007) 1908-1911.

[118] G. Stakkestad, B. Grung, J. Sjöblom, T. Sigvartsen, Colloid Polym. Sci. 277 (1999) 627-636.

[119] G. B. Reartes, P. J. Morando, M. A. Blesa, P. B. Hewett, E. Matijevic, Chem. Mater. 3 (1991) 1101-1106.

[120] G. Stakkestad, L. Bergflodt, J. Disper. Sci. Technol. 21 (2000) 129-143.

[121] S. Kaji, N. Sakamoto, Solid State Ionics 108 (1998) 235-240.

[122] L. F. G. Setz, S. R. H. Mello-Castanho, M. T. Colomer, R. Moreno, Solid State Ionics 180 (2009) 71-75.

[123] L. F. G. Setz, I. Santacruz, M. T. Colomer, R. Moreno, S.R.H. Mello-Castanho, Cerâmica 57 (2011) 237-243.

[124] L. F. G. Setz, S. R. H. Mello-Castanho, Mater. Sci. 
Forum 660-661 (2010) 1145-1150.

[125] J. Kotás, Z. Stasicka, Environm. Pollut. 107 (2000) 263-283.

[126] P. Radhakrishnamurty, P. Adaikkalam, Corros. Sci. 22 (1982) 753-773.

[127] D. Yoon, B. I. Lee, J. Am. Ceram. Soc. 87 (2004) 1066-1071.

[128] L. F. G. Setz, S. R. H. Mello-Castanho, Processamento Coloidal de Cromito de Lantânio, Tese Dr., Instituto de Pesquisas Energéticas e Nucleares, USP, S. Paulo, Brasil (2009).

[129] N. M. Sammes, C. E. Hatchwell, Mater. Lett. 32 (1997) 339-345

[130] L. F. G. Setz, I. Santacruz, M. T. Colomer, S. R. H.
Mello-Castanho, R. Moreno, Mater. Res. Bull. 46 (2011) 983-986.

[131] M. W. Murphy, T. R. Armstrong, P. A. Smith, J. Am. Ceram. Soc. 80 (1997) 165-170.

[132] L. F. G. Setz, I. Santacruz, M. T. Colomer, S. R. H. Mello-Castanho, R. Moreno, J. Eur. Ceram. Soc. 30 (2010) 2897-2903.

[133] S. Zhuiykov, Nanostructured Semiconductor Oxides for the Next Generation of Electronics and Functional Devices - Properties and Applications, $1^{\text {st }}$ ed., Woodhead Publ. Ltd., Cambridge (2014).

[134] K. Huang, J. B. Goodenough, Solid Oxide Fuel Cell Technology - Principles, Performance and Operations, Woodhead Publ. Ltd., Cambridge (2009).

(Rec. 31/10/2014, Rev. 21/11/2014, Ac. 21/11/2014) 